\title{
An Exploratory Study on Environmental Management Practices among Food and Beverages Processing Industries in Pakistan
}

\author{
${ }^{\text {a }}$ Syed Ali Raza Shah, ${ }^{\text {a }}$ Abdullah Mengal, ${ }^{\text {a }}$ Rashid S. Mohammad, ${ }^{\text {b }}$ Obed Rashdi Syed \\ a: Mechanical Engineering Department, Balochistan UET, Khuzdar \\ b: Azman Hashim International Business School, Universiti Teknologi Malaysia
}

\begin{abstract}
Increasing demand for energy, food, and water has resulted in resource depletion. The Sustainable Consumption and Production (SCP) is becoming a big challenge for the developing countries like Pakistan. Being an agrarian country, the food sector is considered an important segment for the socio-economic development. Currently, the Pakistanis behind in resource efficiency as compare to other Asian countries. Environmental Management System (EMS) acknowledged as a key element to promote organizational sustainability. Previous studies elaborated that the main environmental problems related to food manufacturing are, solid wastes, water wastes, air emissions, noise, odor, and a huge consumption of energy and water. Thus, SCP practices provide safe and sustainable human settlements, and helps in reduction of wastages. In this study, Semi-structured interviews were conducted from the owners/managers in the food and beverages processing industries of Pakistan. Purposive with snowball sampling techniques were used to investigate the existing practices of environmental management, barriers and motives towards implementation of EMS. The main problems identified were lack of awareness, weak implementation of environmental regulations, and higher cost of certification, complex documentation procedures, and unavailability of latest technologies accordingly, the study presents managerial implications to overcome the above mentioned issues.
\end{abstract}

Keywords- Environmental Management; Food and Beverage Industry; Pakistan

Date Received 02-10-2019

Date Accepted 25-12-2019

Date Published 31-12-2019

\section{INTRODUCTION}

$\mathrm{G}$ rowing population, water scarcity, food insecurity, and Jenvironmental degradation are considered as the major challenges of twenty-first century. Moreover, the production practices not up to the mark pose negative impact on environment. Therefore, governments, Environmental Protection Agencies (EPA), media, Non-Governmental Organizations (NGOs), and general public increasing pressure on manufacturing industries to make their products in a more sustainable way. Manufacturing sector is growing fast and considered as one of the major source, which pollutes environment from different production processes $[1,2]$.

Food processing is an important sector, since the demand for food is increasing with the increasing population. The production practices of food processing is transforming from a traditional to higher-value-added products. Beside the advantages of food processing, this industry utilizes abundant resources of energy, and water and considered as the major source which pollutes the environment [3, 4].

Pakistan being an agrarian country is rich in agricultural production. The Food industry of the country is the major industry that contributes significant share in socio-economic development [5]. The trend of processed foods is increasing with increasing demand from the customers. Less research work has been carried out about environmental management practices, especially in food and beverages sector. In order to observe the real problem faced by the food processing industry, an exploratory study was conducted in the major industrial cities of Punjab, Pakistan. . The main purpose of exploratory study was to investigate the level of awareness about environmental management practices, barriers, and motive for the implementation of an Environmental Management System (EMS).

\section{LITERATURE REVIEW}

Pakistan food and beverage industry is considered to be the largest industry with an export potential of $13.2 \%$ of total exports. The food and allied products accounts for $27 \%$ of value-added production [6]. Pakistan food and beverages industry is involved in various productions such as:

- Bakery items: breads, buns, biscuits, cakes, nimko, jams, marmalades, burgers, patties, pastries, ketchups, sausages, different kind of sweats, and dry vermicelli.

- Confectionery items: toffees, candies, jellies, bubble gums, chocolates, pop corns, pops, and puddings.

- $\quad$ Chicken meat items: chicken nuggets, sausages, shami kebabs, chicken samosa, spring rolls, and frozen foods.

- Dairy items: ice cream, butter, juices, ultra-high-temp (UHT) milk, creams, dry milk powder, tea whiteners, 
and flavored milk.

- Beverages: carbonated soft drinks, juices, cola, lemon malts, refreshing syrups, fruity malts, soft drinks, tetra pack juices, squashes, sauces, mineral water, and vinegars [7].

Furthermore, the country is rich in the production of rice, wheat, sugar cane, milk, and different kind of fruits and vegetables such as mango, apple, orange, banana, tomato, carrot, and chillies. Food and beverage sector has a great export potential but due to unavailability of international certification, this sector is facing obstacles in international trade where provision of quality, environmental, and other certifications is one of the mandatory requirements [5].

Beside advantages of processed food, this industry consumes abundant resources of energy and water while polluting the environment through solid and water wastes, air and noise pollution.. Additionally, the inefficient production and consumption practices contribute lot of environmental pollution through food processing losses, food wastes, and packing materials [3]. Moreover, the study of Aamir, et al. [8] mentioned about the food wasted pattern across all developing countries and estimated the value around US $\$ 310$ billion. Similarly, the problem of food wastage is increasing in Pakistan and as per estimations $40 \%$ of the cooked food gets wasted.

Pakistan is experiencing rapid growth in population and urbanization. The ineffective usage of natural resources and unplanned developments posing negative impacts on Pakistan's socio economic development. [9]. According to Ortolano, et al. [10] awareness about environmental regulation is weak especially in SME sector that not follows the environmental regulations as supposed to meet. Nadeem and Hameed [11] also stated that, the implementation of environmental regulations is weak in Pakistan. Therefore, this study is important to be conducted for examining the level of awareness, barriers, and motive towards the implementation of an EMS.

\section{A. Environmental Management System}

Rio Declaration on environment and development summiting 1992, which enforced organizations to reduce their environmental impacts and focus largely on sustainable development. The summit suggested that sustainable development should be included as an integral part of every country's policy [12]. According to Chan [13], EMS has an ability to control the company's environmental impact. It works on the Deming model of quality management, which consists of a cycle of four phases: plan, do, check, and act. Moreover, Bhattacharyya and Cummings [14] mentioned that EMS enables organizations to develop strategies for the reduction of environmental impact and associated organizational costs. This may increase the long term value of the firm thereby increasing competitiveness, profitability and share price. In addition, Massoud, et al. [15] stated that the main purpose of the EMS is to organize environmental work in such a way that organization's environmental performance can improve continuously. Highlighting the environmental issues related to food processing Massoud, et al. [15] also stated about high water consumption, discharge of high strength effluents, and consumption of energy as main issues, however, some food industries also produce solid waste, noise, and odor pollutants. Thus, there is a dire need to examine the environmental awareness and barriers towards implementation of EMS. Therefore, this study is focused on food and beverage industry which is a dynamic sector with great export potential.

\section{Methodology}

In this study, a qualitative approach comprising semistructured interviews with open-ended questions is used. Moreover, various interviews were conducted with the owners and managers of food processing industries. Open-ended questions allow the interviewed participants to provide relevant information and share their understandings about the subject [16]. The exploratory nature of study enabled the usage of sampling techniques about non-probability, purposive and snowball sampling strategies [1]. The interview questions were based on three themes of EMS, namely:1) Awareness; 2) Barriers; and 3) Motives and benefits.

Initially, the food and beverages processing industries were purposively selected from the database of Pakistan Chamber of Commerce and Industry (PCCI). The researchers of this study contacted person in-charges through telephone by explaining the purpose of visit and interview. Once initial approval was granted by the food and beverages industries, the interviews were conducted using snowball sampling strategy. Access to ten food and beverages processing industries in the Punjab province of Pakistan was granted.

Face-to-face interviews were conducted with the participants. Unexpectedly, all the participants were reluctant to the voice-recording of the interviews. Therefore, all the interview responses were recorded using handwritten notes all the responses were compiled together and carefully reviewed to ensure that no important information is being missed.

Table I presents a brief overview of the selected industries. Information in the table includes the size of industry, type of processing, export involvement, availability of Environmental Management System ISO-14001, National Environmental Quality Standards (NEQS) local, and interviewee's role in each selected industry.

Moreover, Table I shows that out of ten selected industries, five were large-sized industries. Two were involved in food processing, one was involved in beverages processing, and two were involved in both food and beverages processing. The rest five industries were small and Medium Enterprises (SMEs), among them two were involved in food processing, two were involved in beverages processing and one was involved in both food and beverages processing. Among all ten participants, five were quality managers, two were food technologists, two were owners, and one was production manager. 
Brief Overview of the Selected Industries

\begin{tabular}{|c|c|c|c|c|c|c|c|c|c|c|c|}
\hline \multicolumn{2}{|c|}{ 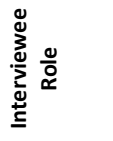 } & $\sum_{0}$ & $\sum_{0}$ & 艺 & $\sum_{0}$ & ᄂ & $\sum_{0}$ & $\sum_{0}$ & ôّ & 亗 & $\sum_{0}$ \\
\hline \multicolumn{2}{|c|}{ 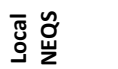 } & ' & $>$ & ' & ' & & $>$ & $>$ & ' & & $>$ \\
\hline \multicolumn{2}{|c|}{ 吅㝘 } & ' & ' & ' & ' & ' & $>$ & $>$ & ' & & \\
\hline \multirow{2}{*}{ 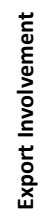 } & 울 & $>$ & ' & $>$ & ' & $>$ & ' & ' & $>$ & $>$ & \\
\hline & $\stackrel{\check{\nu}}{\nu}$ & ' & $>$ & ' & $>$ & ' & $>$ & $>$ & ' & ' & $>$ \\
\hline \multirow{3}{*}{ 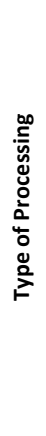 } & 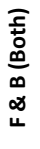 & ' & ' & $>$ & $>$ & ' & ' & $>$ & ' & ' & \\
\hline & 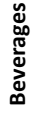 & $>$ & ' & ' & ' & 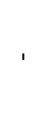 & $>$ & ' & $>$ & ' & \\
\hline & ¿ & ' & $>$ & ' & ' & $>$ & ' & ' & ' & $>$ & $>$ \\
\hline \multirow{2}{*}{ 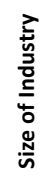 } & $\begin{array}{l}\overline{\bar{\pi}} \\
\bar{\xi}\end{array}$ & $>$ & ' & $>$ & ' & $>$ & ' & ' & $>$ & $>$ & \\
\hline & 品 & ' & $>$ & ' & $>$ & ' & $>$ & $>$ & ' & ' & $>$ \\
\hline \multicolumn{2}{|c|}{$\dot{\Delta ்} 20$} & $r$ & $\sim$ & $m$ & 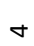 & in & 6 & r & $\infty$ & $\sigma$ & -1 \\
\hline
\end{tabular}

*QM: Quality Manager, FT: Food Technologist, PM: Production Manager

\section{RESULTS AND FINDINGS}

The results of the interviews were divided into three themes. The interviewee discussion and results are presented below.

\section{A. Awareness about Environmental Management System}

The first theme of the study was to explore the level of awareness and existing practices of EMS amongst food and beverages processing industries. The interview results shows that amongst 5 large food and beverage processing industries, two were ISO-14001 certified, two were following the guidelines of NEQS local standards, and one was planning to get certification of EMS in the near future. The interview results of large enterprises are quoted below:

"Our industry is EMS ISO-14001 certified. We got EMS certification, because our industry is located in urban area and effluents are producing Biochemical Oxygen Demand (B.O.D) and Chemical Oxygen Demand (C.O.D). Secondly, we are involved in exports. Beside the other certifications, EMS is one of the mandatory requirement especially trade with European Union". (Large Industry 3)

Similarly, the quality manager of the large food and beverages processing industry stated:

"Our industry is large and consumes more water, energy and producing solid wastes, therefore we got EMS ISO-14001 certification to use these resources in a better manner and improve environmental performance of the industry". (Large Industry 4)

The results from large industries reveled that, large industries were well awared about EMS, and most of them having EMS certification NEQS local or ISO-14001.

The results from SMEs showed that, the SME sector was less awared about EMS and none of the visiting SME had NEQS or ISO-14001 certification. The participant of one of the small enterprise stated:

"Our employees are not aware about EMS. It's not the legal requirement". (SME 2)

Moreover, one of the SME owners of beverages industry mentioned:

"This is a small company; our workers are not highly educated. We are not aware about EMS". (SME 4)

However, one of SME owner, who had some knowledge about EMS replied:

"Our SME is not producing any toxic material. Certification cost is high. We are already facing energy crisis and heavy taxes". (SME 5)

The interview results from the SMEs showed that, SME sector was less awared about EMS. It can be concluded from the interview results and discussion with owners/managers that awareness about environmental regulation is weak. The results are consistent with previous studies [10, 17]. Therefore, governmental organizations responsible for environmental protection, non-governmental organization (NGOs) and policy maker need to focus on this issue, because awareness is the first step towards successful implementation of EMS.

\section{B. Barriers towards weak implementation}

The second theme of the study was to investigate about the barriers towards implementation of EMS in food and beverages processing industries. The interview results from large industries are presented. The quality manager from large food processing industries as mentioned in Table 1:

"ISO-14001 is voluntary standard. Government is not pressurizing for adoption and also no demand from our customer. Customers only focus on quality certification whereas and the documentation procedure is also complex".

But participant from large beverage processing (Large Industry 3) organization replied:

"Our industry is located in urban area and effluents are directly discharged in nearby stream. EPA enforced our industry to control the environmental pollution. Now our industry had NEQS and ISO-14001certifications and effluents are properly treated before discharge". 
The interview results from large industries revealed that there is no legal requirement. While complex documentation procedures are the main barriers. Some of the respondents also suggested that the local NEQS standards need to be revised and all the stake-holders should be taken on-board for preparation. It was also suggested that stakeholders need to be involved in decision making process for successful implementation of environmental regulation.

As compare to large organizations, the interview results from the SME sector indicated more barriers towards successful implementation of an EMS. The respondents from SME sector highlighted the potential barriers such as lack of government support, high cost of certification, customer awareness and no legal requirement. It was also observed from site visit that SMEs were using old and inefficient equipment, which were causing more energy consumption. The water usage pattern was also found inefficient including more water wastages from different processes. Discussing on these issues participants mentioned about lack of resources and heavy taxes and purchase of new and efficient equipment. The participant further mentioned that their workers were not highly qualified and were not aware about EMS. The interview results from SME participants are addressed below.

The participant from SME (1) mentioned:

"EMS ISO-14001 is a new and voluntary standard. Certification cost is high; we do not have enough budget and resources for its implementation. Our customer's never inquired about it".

Similarly, SMEs owners from 4 and 5 mentioned:

"Certification cost is high, without government support we are unable to adopt EMS. Secondly the documentation procedure is more complex".

"Our customer's never demanded for EMS certification. Customers only demands for quality certification. Governmental organizations related to environmental protection never asked for EMS or ISO-14001. However, the officials from food authority visit the SMEs for quality assurance".

The interview results revealed that large organizations having enough resources, manpower, skilled labour, and mostly involved in exports, therefore they adopted local NEQS or EMS ISO-14001. The SME sector lacked in implementation of EMS mainly because of limited resources, awareness, noncustomer requirement, higher certification cost, complex documentation procedure, obsolete technologies, and lack of government support... The mentioned results of this study are consistent with the previous studies $[15,16,18]$.

\section{Motives and Benefits for implementation}

The third theme of the study included the motives and the benefits for implementation of EMS in food and beverages processing industries. The interview results showed that large organization were more awared about the benefits as compare to SME. The interview response from the large organization (1) is mentioned below:

"EMS improves the company image and provide competitive environment".

Similarly, the respondents from the large organizations highlighted the motives and benefits of EMS as it is required for exports The interview results from large organizations (3), (4) and (5) are quoted below:

"EMS provides competitive environment, reduces wastages, increase profits, and provide higher customer satisfaction".

"EMS provides cost reductions and fulfill customer requirements, minimizes waste, and increase environmental performance".

"EMS helps in minimizing the energy and water usage, reduce pollution and wastes".

On the other hand the interview results from the SMEs found dissimilar. The results from SMEs showed that most of them were not aware about EMS benefits. One of the reasons could be their non-involvement in exports, and non-significant benefits. Mostly the owners and managers were seeking support from government for imparting awareness and training seminars on EMS relevant benefits to them and vice versa.

The results from SMEs are presented below. The participant from SME (1) replied:

"Since we are not ISO or NEQS certified, we have no idea about the EMS benefits".

Similarly SME (2) participant mentioned:

"EMS is mandatory requirement only for export and we are not involved in exports".

Moreover, the owners of the SMEs (4) replied:

"Government should support the SMEs. Provide us soft loans for implementation".

The SME owner (5) desires for awareness seminars and mentioned:

"We need financial help from government. Training and awareness seminars should be arranged. Especially, awareness about environmental issues related to food and beverages processing".

The interview results of motives and the benefits for implementation of EMS indicated that large industries were more aware about the benefits and motive mainly because of their export involvement and attaining significant benefits, whereas SMEs were lacking in both the aspects.. The quality manager () from SME suggested that trainings and awareness programs of the owners about the tangible financial benefits of EMS. The interview results for the motives and befits are consistent to previous studies $[15,19,20]$.

The overall interview results of all themes: awareness, barriers, and motives and benefits of EMS are presented below in Table II.

TABLE II

Barriers, motives and benefits of EMS

\begin{tabular}{|l|l|}
\hline \multicolumn{1}{|c|}{ Barriers } & \multicolumn{1}{|c|}{ Motives and benefits } \\
\hline - Lack of awareness & - Improves company image \\
- Lack of government support & - Higher customer \\
- Not a legal requirement & satisfaction \\
- Higher cost of certification & - Mandatory requirement for \\
- Complex documentation & exports \\
procedure & - Financial benefits \\
- Lack of skilled persons/staff & - Increases production \\
\hline
\end{tabular}




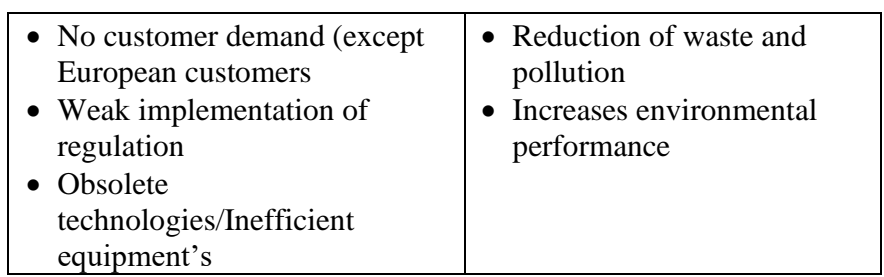

\section{MANAGERIAL IMPLICATION}

The findings of this study identified several barriers towards successful implementation of EMS in food and beverages manufacturing industries in Pakistan. In order to eliminate the barriers, the governmental authorities such as federal and provincial EPAs may need to impose proper regulation and provide technical support to the industries for enabling the EMS system. In addition, governmental authorities may need to provide awareness programs for industries in remote areas by organizing seminars and training workshops for managerial practitioners, especially in the industries that cause environmental issues through their production.

The owners and managers of SMEs, in particular, have notified the lack of resources and budget issues. They also showed their interest in seeking government support to materialize their EMS practices. Therefore, the government authorities may also need to provide financial support to small firms to implement EMS systems. Furthermore, the authorities may also need to stimulate the NGOs to put their efforts and resources by providing technical assistance especially to SMEs so that they can easily implement the EMS.

At organizational level, the managers in industries may need to spread the awareness among their employees about the environmental regulations and the way EMS could help to achieve their organizational goals. We particularly suggest the policy-makers and researchers of environmental management to stress more on the SME sector, because this sector requires more supports and awareness about environmental issues and their consequences. Environmental issues and the impacts may also be spread using social and print media, and NGOs working on environment protection.

\section{CONCLUSION}

The study showed the current practices, barriers and motives for EMS in food and beverages processing industry in Pakistan. The results revealed that in comparison of SMEs, large industries are more awared about environmental issues, environmental regulations, and they are getting benefit from NEQS local or EMS ISO-14001 certifications. However, the SME sector shows lack of awareness and importance. The SME owners and managers notified that the cost of certification, inefficient equipment, no legal requirement, and no customer demand were the main barriers towards EMS system practices. We have found additional evidence such as complex documentation procedure is also a barrier.
The owners and managers in large industries highlighted company image, mandatory requirement for export, better performance, reduce cost and improve environmental performance as motives and benefits. Similar motives and benefits were not found in SMEs, whilst they were seeking for governmental support in terms of financial backup and awareness programs for implementation. In addition, some of the owners and managers also expected government authorities to provide trainings and awareness seminars for EMS, especially environmental issues in food and beverages processing. It is pertinent to mention that $90 \%$ of the country business comes under SME category, and this sector is considered as backbone of the country. Similarly, food and beverage sector is important and growing rapidly.. Therefore, this sector needs special attention by the authorities because of the increasing demand of the quality food.

The current study has some limitations. Firstly, due to time and resource constraints, the present study explored industries from only one province i.e. Punjab, Pakistan. Therefore, it is suggested that similar studies may be conducted in other provinces of the country. Secondly, the study selects only food and beverage as research context. Future research could select other sectors and explore findings to enhance the environmental awareness across different industries. Furthermore, the current study used qualitative interviews to explore concerns of owner and managers in ten industries. Future research could expand the scope by selecting various industries using quantitative methods to generalize and validate the findings.

\section{REFERENCES}

[1] A. I. Wahga, R. Blundel, and A. Schaefer "Human Capital and Environmental Engagement of SMEs in Pakistan: A Comparative Analysis of the Leather Industry," in ISBE Annual Conference, Glasgow, 2015

[2] C. Alayón, K. Säfsten, and G. Johansson, "Conceptual sustainable production principles in practice: Do they reflect what companies do?," Journal of Cleaner Production, vol. 141, pp. 693-701, 2017.

[3] A. A. Alsaffar, "Sustainable diets: The interaction between food industry, nutrition, health and the environment," Food Science and Technology International, vol. 22, pp. 102-111, 2016.

[4] M. A. Augustin, M. Riley, R. Stockmann, L. Bennett, A. Kahl, T. Lockett, et al., "Role of food processing in food and nutrition security," Trends in Food Science \& Technology, vol. 56, pp. 115-125, 2016.

[5] MOF. (2017, 15-05-2017). Agriculture Sector. Available: http://www.finance.gov.pk/survey/chapters_16/02_Agriculture.pdf

[6] H. Amir, J. Moiz, and F. N. Baig, "The food processing sector in Pakistan," Institute of Business Administration (IBA) Karachi2014.

[7] Punjab Skill Development Fund. (2015, 16-12-2017). Food Processing Sector Skills Study. Available: https://psdf.org.pk/wpcontent/uploads/2015/12/Food-Processing-Report-1-1.pdf

[8] M. Aamir, H. Ahmad, Q. Javaid, and S. M. Hasan, "Waste Not, Want Not: A Case Study on Food Waste in Restaurants of Lahore, Pakistan," Journal of Food Products Marketing, vol. 24, pp. 591-610, 2018.

[9] R. Saeed, A. Sattar, Z. Iqbal, M. Imran, and R. Nadeem, "Environmental impact assessment (EIA): an overlooked instrument for sustainable development in Pakistan," Environtal monitoring and assessment, vol. 184, pp. 1909-19, 2012.

[10] L. Ortolano, E. Sanchez-Triana, J. Afzal, C. L. Ali, and S. A. Rebellón, "Cleaner production in Pakistan's leather and textile sectors," Journal of Cleaner Production, vol. 68, pp. 121-129, 2014.

[11] O. Nadeem and R. Hameed, "Evaluation of environmental impact assessment system in Pakistan," Environmental Impact Assessment Review, vol. 28, pp. 562-571, 2008. 
[12] I. Mezinska and S. Strode, "Emerging Horizons of Environmental Management in Food Sector Companies," Procedia - Social and Behavioral Sciences, vol. 213, pp. 527-532, 2015.

[13] E. S. W. Chan, "Barriers to EMS in the hotel industry," International Journal of Hospitality Management, vol. 27, pp. 187-196, 2008.

[14] A. Bhattacharyya and L. Cummings, "Measuring Corporate Environmental Performance - Stakeholder Engagement Evaluation," Business Strategy and the Environment, vol. 24, pp. 309-325, 2015.

[15] M. A. Massoud, R. Fayad, M. El-Fadel, and R. Kamleh, "Drivers, barriers and incentives to implementing environmental management systems in the food industry: A case of Lebanon," Journal of Cleaner Production, vol. 18, pp. 200-209, 2010.

[16] A. Saad, D. Su, P. Marsh, and Z. Wu, "Total Quality Environmental Management toward Sustainability: Need and Implementation in Libyan food Industry," Key Engineering Materials, vol. 572, pp. 84-89, 2014.

[17] A. I. Wahga, R. Blundel, and A. Schaefer, "Understanding the drivers of sustainable entrepreneurial practices in Pakistan's leather industry: A multi-level approach," International Journal of Entrepreneurial Behavior \& Research, vol. 24, pp. 382-407, 2018.

[18] M. Matouq, "A Case-study of ISO 14001-based Environmental Management System Implementation in the People's Republic of China," Local Environment, vol. 5, pp. 415-433, 2010.

[19] M. Lozano and J. Valles, "An analysis of the implementation of an environmental management system in a local public administration," J Environ Manage, vol. 82, pp. 495-511, 2007.

[20] L. P. Tan, "Implementing ISO 14001: is it beneficial for firms in newly industrialized Malaysia?," Journal of Cleaner Production, vol. 13, pp. 397-404, 2005

\section{(c) (i) \\ Journal of Applied and Emerging Sciences by BUITEMS is licensed under a Creative Commons Attribution 4.0 International License.}

